\title{
Emergency Laparotomy Follow-Up Study (ELFUS): prospective feasibility investigation into postoperative complications and quality of life using patient-reported outcome measures up to a year after emergency laparotomy
}

\author{
D. I. Saunders ${ }^{1 *}$ (D, R. C. F. Sinclair ${ }^{1}$, B. Griffiths' ${ }^{2}$ E. Pugh ${ }^{1}$, D. Harji ${ }^{2}$, B. Salas ${ }^{3}$, H. Reed ${ }^{4}$ and C. Scott ${ }^{4}$
}

\begin{abstract}
Background: Emergency laparotomy carries a significant risk profile around the time of surgery. This research aimed to establish the feasibility of recruitment to a study using validated scoring tools to assess complications after surgery; and patient-reported outcome measures (PROMs) to assess quality of life and quality of recovery up to a year following emergency laparotomy (EL).

Methods: We used our local National Emergency Laparotomy Audit (NELA) register to identify potential participants at a single NHS centre in England. Complications were assessed at 5, 10 and 30 days after EL. Patientreported outcome measures were collected at 1, 3, 6 and 12 months after surgery using EQ5D and WHODAS 2.0 questionnaires.

Results: Seventy of 129 consecutive patients (54\%) agreed to take part in the study. Post-operative morbidity survey data was recorded from 63 and 37 patients at postoperative day 5 and day 10. Accordion Complication Severity Grading data was obtained from 70 patients. Patient-reported outcome measures were obtained from patients at baseline and 1, 3, 6 and 12 months after surgery from 70, 59, 51, 48, to 42 patients (100\%, 87\%, 77\%, $75 \%$ and $69 \%$ of survivors), respectively.
\end{abstract}

Conclusions: This study affirms the feasibility of collecting PROMs and morbidity data successfully at various time points following emergency laparotomy, and is the first longitudinal study to describe quality of life up to a year after surgery. This finding is important in the design of a larger observational study into quality of life and recovery after EL.

Keywords: Quality of life; Emergency laparotomy, Complications, Patient-reported outcome measures (PROMS)

\footnotetext{
* Correspondence: david.saunders8@nhs.net

* presented in part at Association of Anaesthetists of Great Britain and Ireland Winter Scientific Meeting, London, January 2020

'Department of Anaesthesia, Royal Victoria Infirmary, Newcastle upon Tyne NHS FT, NE1 4LP, UK

Full list of author information is available at the end of the article
}

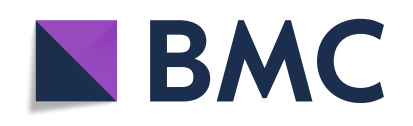

(- The Author(s). 2021 Open Access This article is licensed under a Creative Commons Attribution 4.0 International License, which permits use, sharing, adaptation, distribution and reproduction in any medium or format, as long as you give appropriate credit to the original author(s) and the source, provide a link to the Creative Commons licence, and indicate if changes were made. The images or other third party material in this article are included in the article's Creative Commons licence, unless indicated otherwise in a credit line to the material. If material is not included in the article's Creative Commons licence and your intended use is not permitted by statutory regulation or exceeds the permitted use, you will need to obtain permission directly from the copyright holder. To view a copy of this licence, visit http://creativecommons.org/licenses/by/4.0/. The Creative Commons Public Domain Dedication waiver (http://creativecommons.org/publicdomain/zero/1.0/) applies to the data made available in this article, unless otherwise stated in a credit line to the data. 


\section{Introduction}

Major non-elective abdominal surgery ("emergency laparotomy, EL”) leads to a long hospital admission and carries a significant risk of mortality at 30 and 90 days after surgery $(9.6 \%$ and $12.9 \%$ respectively) (National Emergency Laparotomy Audit 2019). Patients are frequently elderly ( $45 \%$ age 70 or above), have co-morbidity (over half are graded ASA3 or above), and present in an acutely unwell condition (over half are deemed to have a predicted risk of mortality of over 5\%) (National Emergency Laparotomy Audit 2019). The development of a mandatory data registry, the National Emergency Laparotomy Audit (NELA), has enabled systematic recording of process and outcome measures for patients undergoing EL in England and Wales since 2013. The most recent annual report from NELA analysed 24000 patients from 179 hospitals who underwent emergency surgery in 2018 (National Emergency Laparotomy Audit 2019). Despite significant improvements since the first UK report into patient outcomes (Saunders et al. 2012), mortality remains high at $9.6 \%$, with a prolonged median length of hospital stay of 16 days. NELA has a contractual obligation to limit the burden of data-entry for clinicians, and the outcomes dataset within the registry is restricted to short-term findings only. Despite the potential importance to patients and their families, detail about early post-operative morbidity, or the impact of EL on a patient's longer-term functional ability and quality of life (QoL) is recorded in NELA at best in low fidelity, or not at all.

Patient-reported outcome data provides a more balanced and patient-centric perspective of treatment effects and their potential benefits beyond traditional clinical outcomes. Patient-reported outcome measures (PROMs) are routinely and successfully collected in the NHS in the elective setting in a number of conditions including hip and knee arthroplasty [NHS Digital Patient Reported Outcome Measures, 2020]. Collection of PROMs in the emergency setting is potentially challenging given the acute nature of disease presentation combined with deranged physiology and the time-sensitive need to deliver definitive treatment. Heterogeneity of disease presentation and duration, coupled with the immediacy of the clinical setting makes accurate capture of baseline QoL assessment difficult.

The current data about QoL following EL is limited to a few studies, with little robust data available. Stevens et al. described variable PROMs reporting in clinical trials conducted in the emergency setting, with the use of multiple outcome measures, limited baseline data and a lack of a priori hypotheses (Stevens et al. 2016). Blazeby et al. studied the feasibility of collecting PROMs in the emergency setting, collecting data on all patients presenting with emergency pathology irrespective of treatment modality (Mason et al. 2015). This group reported good baseline compliance; but high rates of attrition led to limited reporting of longitudinal data (Mason et al. 2015). Kwong et al. investigated the feasibility of collecting cross-sectional retrospective generic and disease specific QoL data in patients who had been registered in NELA (Kwong et al. 2018). They recruited 268 patients from 13 hospitals and made contact with 255 survivors 3 months after surgery. The overall response rate was $74.1 \%$, adding to the emerging evidence base about the feasibility of this approach in the emergency setting (Kwong et al. 2018). The same group also studied their ability to collect retrospective baseline PROMs in medical emergencies (acute myocardial infarction) (Kwong and Black 2018). Ninety percent of those invited to participate agreed to take part, although variation in approaching eligible patients in different hospitals led to recruitment bias. Given the high response rate demonstrated by this group, this may be considered a potentially suitable option in EL patients.

There is a complex interplay between quality of life (QoL) and post-operative clinical outcomes in surgery. Post-operative complications are associated with prolonged recovery, increased length of stay and have an adverse impact on all aspects of QoL (Khuri et al. 2005). Despite its importance to patients and their families, post-operative morbidity is poorly reported in the emergency setting, with the focus being on post-operative mortality. We believe it is important to document postoperative morbidity in patients undergoing EL and to investigate the relationship between morbidity and subsequent quality of life. The aims of the Emergency Laparotomy Follow-Up Study (ELFUS) were to assess the feasibility of collecting accurate, longitudinal QoL data and morbidity in the setting of EL during the first year of recovery prior to considering a definitive, largerscale future study.

\section{Methods}

The study protocol was approved by the Newcastle and North Tyneside Regional Ethics Committee (16/NE/ 0334) and sponsored by Newcastle upon Tyne Hospitals NHS Foundation Trust. ELFUS was designed as a prospective feasibility observational study of in-hospital postoperative complications and post-discharge patient reported outcome measures following emergency laparotomy. Adult patients were recruited during a 7-month period at the Royal Victoria Infirmary (RVI), Newcastle, and followed up for a year after surgery. Eligibility criteria were that the patient had undergone surgery that met inclusion criteria for NELA and that patient data had been entered into our local NELA registry (NELA inclusion criteria, 2013). 
Patients or their relatives/advocates were approached during the first 4 days after EL in either critical care or the general surgery postoperative ward. Written informed consent was taken from each participant, or alternatively from their proxy in the situation where sedation and ventilation prevented capacity to give consent. Participant consent was gained retrospectively for these individuals once capacity was regained.

The World Health Organisation Disability Schedule 2.0 (WHODAS 2.0) [World Health Organisation, 2018] and the EuroQol Five Dimensions (EQ5D) [Euroqual Research Foundation, 2019] questionnaires were used to assess QoL. Study participants in hospital at the relevant timepoints were offered paper copies of the questionnaires, given whatever time they required, and asked to circle their most appropriate answers using a pen. For those who required assistance, and for those who had left hospital, a member of the research team read out the questions either directly at the bedside, or over the telephone, and recorded answers on paper on behalf of the participant. Baseline data were collected at day 5, and longitudinal data were collected at 1, 3, 6 and 12 months post-operatively. The Post-Operative Morbidity Survey (POMS) (Grocott et al. 2007) and the Accordion Severity Grading Classification System (Strasberg et al. 2009) were used to assess post-operative morbidity. POMS assessments were undertaken at postoperative day 5 and day 10; and the Accordion Severity Grading was assessed at 30 days after surgery. A schedule of assessments of complications and QoL at various timepoints is shown in Table 1 . See Additional files 1 and 2 for detail of complications and QoL assessment tools.

\section{Primary endpoint}

Our primary endpoint was feasibility of PROMs and post-operative complication data collection following EL. This was assessed using data compliance, calculated as the proportion of completed questionnaires received at each time point.

\section{Statistics and analytical methods}

The target sample size of 70 patients was determined to allow precise estimation of parameters of interest. Previously, sample sizes of 24-50 have been recommended for use in clinical feasibility studies (Sim and Lewis 2012). The Shapiro-Wilk test was used to confirm nonparametric distribution of patient characteristics. Continuous non-parametric variables were compared using Mann-Whitley $U$ tests. Categorical data were analysed using Fisher's exact test. Minitab 18 software was used for statistical testing.

\section{Results}

Patient recruitment

Of 129 patients screened and assessed for eligibility, 70 patients agreed to participate (recruitment rate of $54.4 \%)$. Twenty-four patients (18.5\%) declined to take part, and 35 were considered ineligible. Reasons for this included not fulfilling NELA inclusion criteria (6 patients); participation in other trials (9 patients); and early discharge from hospital or early death after surgery (8 patients) (Fig. 1). Baseline patient and clinical characteristics are shown in Table 2. Study participants had lower predicted median P-POSSUM and NELA mortality risks compared to those who were not recruited (4.6\% vs $8.8 \%$ and $3.3 \%$ vs $4.1 \%$ respectively).

\section{Data compliance PROMs and post-operative morbidity} Data compliance with WHODAS 2.0 and EQ-5D questionnaires at baseline and at follow-up timepoints is shown in Table 3. Baseline data collected on day 5 postoperatively had a compliance rate of $100 \%$ for PROMS and post-operative morbidity. Data compliance at 12 months for both WHODAS 2.0 and EQ-5D were $69 \%$. Data compliance for the assessment of post-operative

Table 1 Schedule of patient assessments

\begin{tabular}{|c|c|}
\hline Timepoint (post-laparotomy) & Action/assessments \\
\hline Within 4 days of EL (day 0-4) & $\begin{array}{l}\text { Identification of potential study participants } \\
\text { Distribution of participant information sheet } \\
\text { Informed consent taken }\end{array}$ \\
\hline Day 5 & $\begin{array}{l}\text { Baseline assessment of } \text { QoL }^{\mathrm{a}} \text { : WHODAS } \\
\text { POMS }^{\mathrm{a}} \text { and EQ5D }\end{array}$ \\
\hline Day 10 & POMS for those still in-patient \\
\hline Day 30 & $\begin{array}{l}\text { QoL assessment with WHODAS and EQ5D } \\
\text { Accordion Severity Grading Assessment }\end{array}$ \\
\hline 3 months & QoL assessment with WHODAS and EQ5D \\
\hline 6 months & QoL assessment with WHODAS and EQ5D \\
\hline 12 months & QoL assessment with WHODAS and EQ5D \\
\hline
\end{tabular}

${ }^{a} Q o L$ means quality of life, WHODAS means World Health Organisation disability assessment score 2.0, EQ5D means 5-domain Euroqual quality of life assessment, POMS means Post-Operative Morbidity Survey 


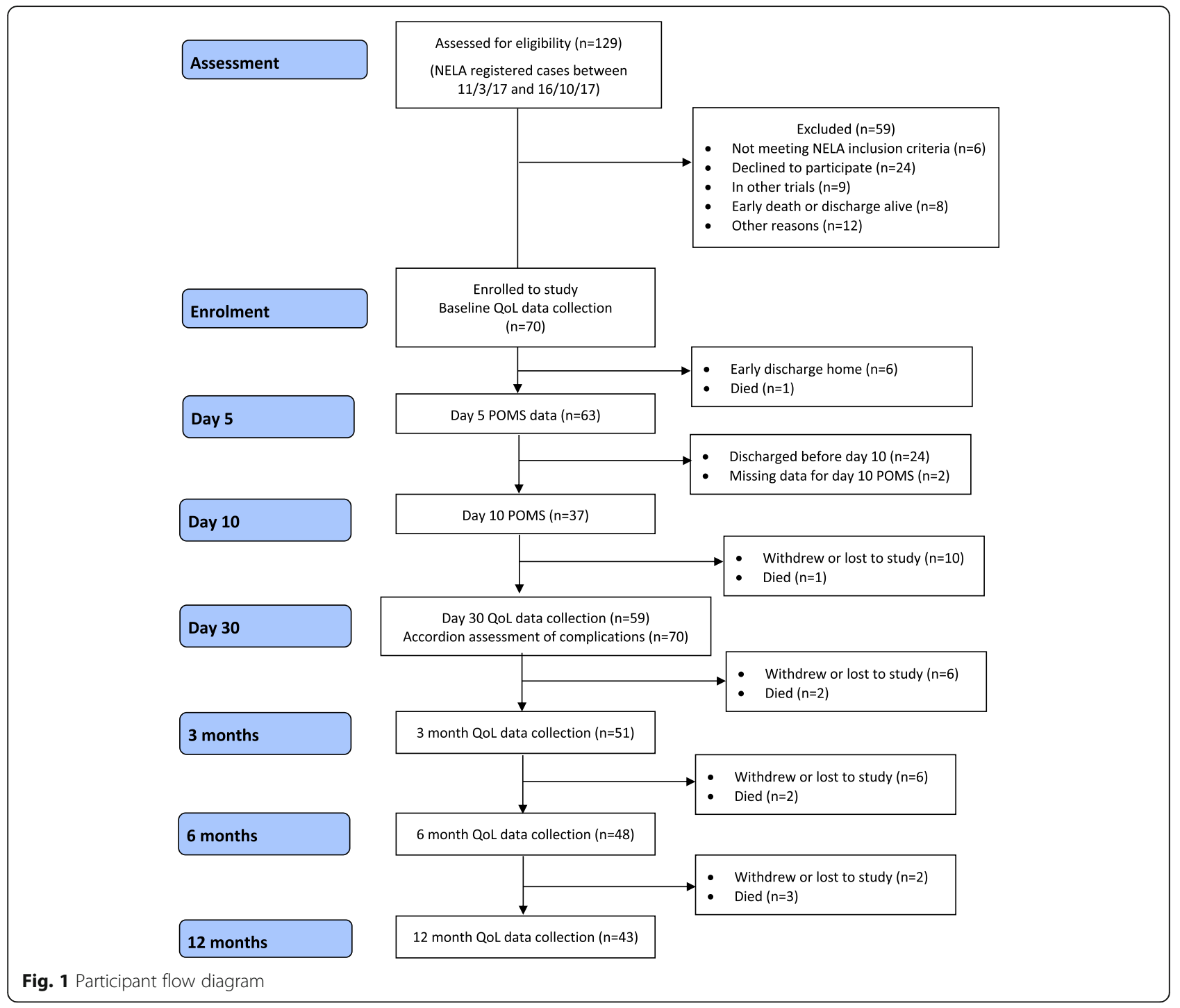

Table 2 NELA registrant and study participant characteristics. Values are number (proportion) or median (IQR [range])

\begin{tabular}{|c|c|c|c|c|}
\hline & $\begin{array}{l}\text { All registrants in NELA during study period } \\
(n=129)\end{array}$ & $\begin{array}{l}\text { Study participants } \\
(n=70)\end{array}$ & $\begin{array}{l}\text { Excluded from study } \\
(n=59)\end{array}$ & $p$ value \\
\hline Age & 66 (50.5-76.5 [21.0-89]) & $65.5(50-76$ [21-89]) & 66 (56-77 [22-88]) & 0.574 \\
\hline P-Possum mortality risk pre-op (\%) & $5.7(2.6-20.1[0.7-98.5])$ & $4.6(1.8-15.6[0.7-83.9])$ & $8.8(4.1-31.8[0.8-98.5])$ & 0.006 \\
\hline P-Possum morbidity risk pre-op (\%) & $69.0(47.5-90.6[17.5-100])$ & $62.1(39.2-86.0[17.5-99.4])$ & $83.5(59.1-94.5[19.9-100])$ & 0.004 \\
\hline NELA mortality risk pre-op (\%) & $3.7(1.2-11.6[0.1-88.9])$ & $3.3(0.9-10.0[0.1-61.3])$ & $4.1(1.6-18.9[0.3-88.9])$ & 0.094 \\
\hline ASA physical status & $3(2-3[1-5])$ & $3(2-3[1-5])$ & $3(2-3[1-5])$ & 0.086 \\
\hline Female patient & $55(42.6)$ & $33(47.1)$ & $22(37.3)$ & 0.287 \\
\hline Critical care stay (days) & $2(2-4[0-52])$ & $2(2-4[0-15])$ & $2(2-5[2-52])$ & 0.383 \\
\hline Return to theatre & $10(7.8)$ & $6(8.6)$ & $4(6.8)$ & 0.754 \\
\hline Postop LOS hospital (days) ${ }^{a}$ & $9.8(5.5-19.4[0-60])$ & $9.3(6.0-23.7[0-60])$ & $11.3(5.4-17.9[0-60])$ & 0.919 \\
\hline Observed In-hospital mortality & $13(10.1)$ & $4(5.7)$ & $9(15.3)$ & 0.085 \\
\hline
\end{tabular}

${ }^{a}$ Length of postoperative stay assessment capped at 60 days 
Table 3 Number of respondents to PROMs questionnaires at different time points

\begin{tabular}{llllll}
\hline & Baseline/enrolment & $\mathbf{1}$ month & $\mathbf{3}$ months & $\mathbf{6}$ months & $\mathbf{1 2}$ months \\
\hline Possible respondents (survivors) & 70 & 68 & 66 & 64 & 61 \\
EQ5D completed questionnaires & 70 & $59(87 \%)$ & $51(77 \%)$ & $48(75 \%)$ & $42(69 \%)$ \\
WHODAS completed questionnaires & 70 & $59(87 \%)$ & $51(77 \%)$ & $48(75 \%)$ & $42(69 \%)$ \\
WHODAS score median (IQR) [range] & $3(1-14)[0-36]$ & $14(8-23)[0-38]$ & $6(1-18)[0-35]$ & $4.5(0-12.5)[0-33]$ & $2(0-19)[0-38]$ \\
Number (proportion) with WHODAS score of zero & $14(20.0 \%)$ & $4(6.8 \%)$ & $9(17.6 \%)$ & $14(29.2 \%)$ & $13(31.7 \%)$ \\
\hline
\end{tabular}

Proportion are numbers of respondents completing questionnaires fully compared to number of possible respondents (survivors)

morbidity using the POMS and Accordion Severity Classification were at least $95 \%$.

\section{WHODAS 2.0}

WHODAS disability scores were calculated for 70 patients at baseline and 42 patients at 12 months. Fourteen (20.0\%) patients were found to have no disability at baseline. At 12-month follow-up, 13 (31.7\%) patients were found to have no disability (Table 3 ). The observed median WHODAS scores across all candidate timepoints were between 3 and 14. Please see Additional file 3 for detail about respondents to various WHODAS domains at candidate time points.

\section{EQ5D}

EQ5D scores were calculated for 70 patients at baseline and 42 patients at 12 months (Table 3). Across all domains, EQ5D identified health problems at baseline, with observed rates of $58.6 \%$ in the pain domain, $47.1 \%$ in the anxiety domain and $41.4 \%$ in the ability to perform usual activities domain. The EQ-5D was able to identify health problems at all candidate timepoints with response rates amongst survivors of $87 \%, 77 \%, 75 \%$ and $70 \%$ at $1,3,6$ and 12 months post-operatively. Please see Additional file 4 for detail about study participants who responded to EQ5D questionnaire domains at candidate time points. Additional file 5 shows the proportion of respondents reporting EQ5D levels $1-5$ at candidate time points; and Additional file 6 shows the proportion of respondents with problems or no problems at candidate time points.

\section{Postoperative complications data}

Six patients were discharged from hospital within 5 days, and one patient died. POMS scores were collected for all 63 remaining in-patients (90\% of study participants) at post-operative day 5 . Thirty-nine patients remained in hospital at day 10, and POMS scores were collected for 37 (52.8\% of study participants). A POMS score of 0 was observed for $15 / 63(23.8 \%)$ patients on day 5 , and $14 / 37$ (37.8\%) on day 10. A breakdown of the types of complications observed is outlined in Fig. 2.

Accordion Severity Grading of complications were collected for all 70 patients who participated in the study. No complications were observed in 39 (55.7\%) patients. Complications of grade 3 severity and above were observed in 19 (27.1\%) patients.

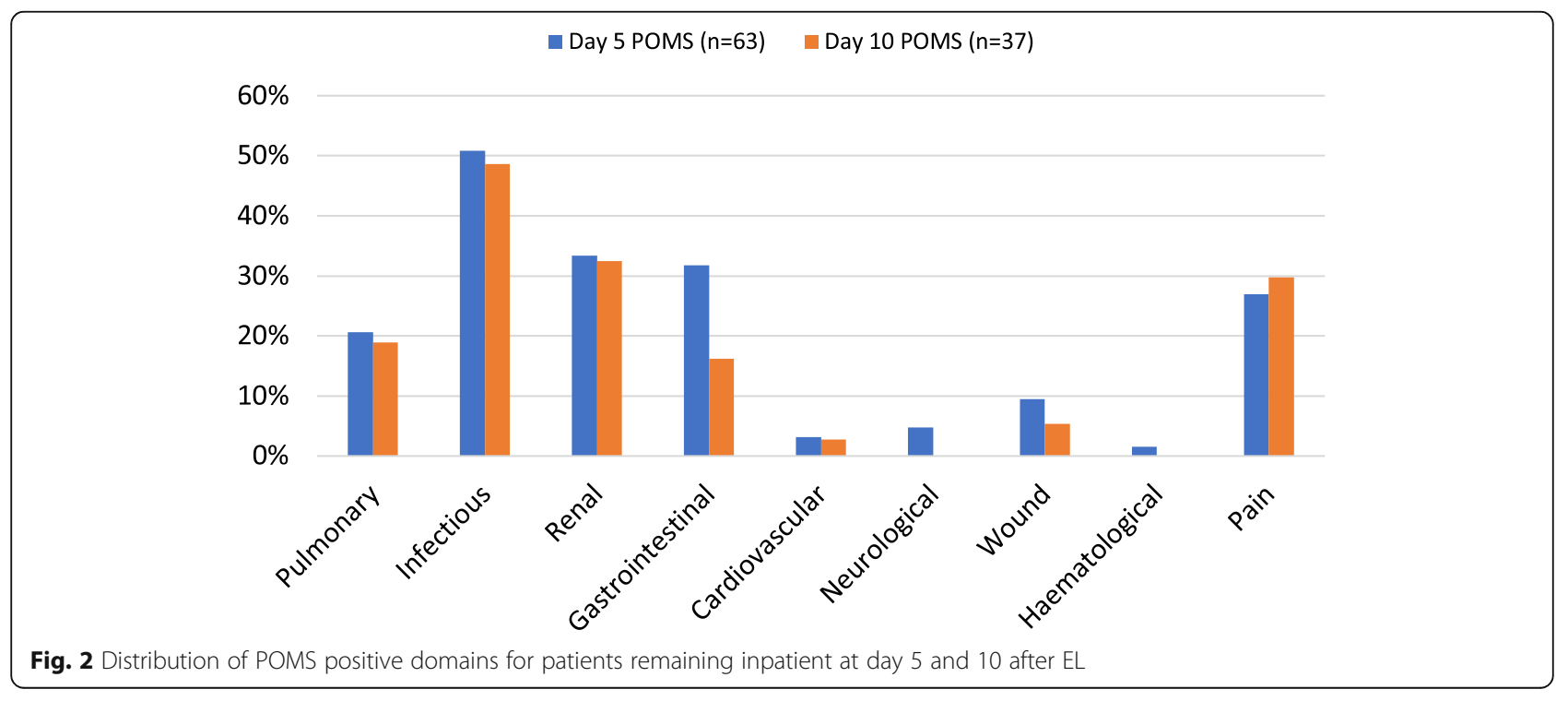




\section{Discussion}

The ELFUS study demonstrates that it is feasible to collect valid and accurate QoL and complication data in patients who have undergone emergency laparotomy.

We were able to recruit $54 \%$ of patients undergoing EL at our institution, and accurately collect baseline and longitudinal 12-month QoL data, with response rates of $100 \%$ and $70 \%$ respectively. Alongside this, we were able to collect accurate and validated 30-day morbidity data in all patients. An important finding in our study is around recruitment bias, with the study cohort expressing less physiological derangement and sickness severity compared to those not recruited, as demonstrated by lower predicted morbidity and mortality risk estimates at the time of surgery.

Previous reports of collecting longitudinal QoL data in the emergency setting have demonstrated high attrition rates at 12 months. Kwong et al. were able to demonstrate response rates of $70 \%$ at 3 months postoperatively, but they did not extend data collection beyond this timepoint (Kwong et al. 2018). Our study reports similar early response rates but demonstrates a consistent response rate of $70 \%$ at 12 months. Preoperative baseline data needs to be reflective of the health status of patients prior to emergency laparotomy. Collecting this data prior to surgery can be difficult due to the time-sensitive need to deliver definitive clinical care. Consequently, we collected our baseline data at 5 days post-operatively. Using this approach, we were able to recruit $54 \%$ of our emergency laparotomy population and collect 100 percent of baseline QoL data. PROMs questionnaires such as WHODAS 2.0 and EQ5D capture QoL over a period of 30 days, so the collection of baseline data at day 5 post-operatively should adequately capture pre-operative QoL and overall health status, prior to assessing the impact of emergency laparotomy.

Morbidity is considered to be an important outcome measure in emergency laparotomy with the widely used Portsmouth Physiological and Operative Severity Score for the enumeration of Mortality and Morbidity (P-POSSUM) scoring system providing predicted post-operative morbidity scores for patients as a part of the preoperative risk stratification process (Prytherch et al. 1998). Despite its emphasis, morbidity is poorly reported as a robust outcome measure in emergency laparotomy, with a varying documented incidence of $33-71 \%$ in the literature (Tengberg et al. 2017; Tolstrup et al. 2017). This may be due to variable outcome reporting, a lack of appropriate definitions and the failure to use available standardised scoring systems. We employed the POMS scoring system to facilitate data collection and to appropriately categorise complications; and the Accordion Severity Scoring System to grade complications. Employing two scoring systems enabled us to categorise complications in $100 \%$ of inpatients on day 5 and $94.9 \%$ of inpatients on day 10 (90\% and $52.8 \%$ of study participants respectively), whilst providing Accordion Severity data in all patients recruited into our study. A modified version of POMS scoring system has been previously used in the emergency setting to assess outcomes over multiple timepoints within a 30-day timeframe. Howes et al. identified that POMS-defined morbidity was highest on day 3 and reduced at each successive time-point (Howes et al. 2015). This reflects our own experience and suggests early collection of inpatient morbidity is key to good outcome reporting of post-operative morbidity. The use of the POMS system in the emergency setting is simple and effective; and should be employed in the early post-operative period. Ensuring consistency in the use of these scoring systems is in line with recent consensus recommendations to include outcome measures so that pooling and meta-analysis of results is facilitated (Myles et al. 2018, Shulman et al. 2015). A larger study using the measures should permit direct comparison of outcomes for EL patients with other patient groups, as well as provide robust information about quality of recovery for EL patients.

Outcome assessment in the emergency setting has begun to look beyond 30- and 90-day mortality to include broader patient-related factors including preoperative frailty. The Emergency Laparotomy and Frailty (ELF) group demonstrated that the presence of preoperative frailty was associated with a greater risk of post-operative mortality and morbidity (Parmar et al. 2019). Routine collection of frailty scores have been introduced into the current NELA dataset (National Emergency Laparotomy Audit 2019). Outcome reporting in the emergency setting should be expanded further to include QoL, with a particular emphasis on physical impact, functional impairment and the presence or lack of disability. QoL is an important outcome measure in its own right, but also of importance is a need to measure freedom from impairment or disability, especially as the very point of surgery is to relieve suffering and to cure a state of disease (Shulman et al. 2015). Disability-free survival is an attractive outcome measure for studies of the impact of surgery, as it reflects the primary goal for most patients and has been recommended as a meaningful endpoint in studies of surgical patients (Chalmers et al. 2001). This outcome measure could be used to help develop and refine rehabilitation and recovery programmes in the future, as well as informing pre-operative discussions around the time of emergency laparotomy (Glance et al. 2014). WHODAS 2.0 is measure of physical function and disability and has been used to define disabilityfree survival after surgery (Shulman et al. 2015). Using WHODAS 2.0, we were able to identify functional 
impairment in $56(80.0 \%)$ patients at baseline and 30 (69.7\%) patients at 12 months. The measure was able to identify patients with a range of scores, which reflects differing levels of disability. The wider utility of this measure in the emergency surgery setting needs further investigation, to assess the definitive impact of emergency laparotomy on functional and physical outcomes amongst patient groups of varying age, co-morbidity, pathology and sickness severity at the time of surgery.

The recruitment bias in our study is an important consideration in future work. Recruiting a truly representative cohort of emergency surgery patients is difficult given overriding clinical priorities in the acute and initial phases of their clinical course. Further work must be undertaken to identify how this critically unwell population cohort can be included into emergency surgery research frameworks to ensure wider generalisability. At the inception of NELA, exemption for patient consent was granted under section 251 of the 2006 NHS act, acknowledging that recruiting high risk patients into the registry at a time of acute illness would be problematic were consent to be required. One possible solution to the recruitment bias we experienced in our study would be to add additional patient-centric outcome measures to the dataset of NELA, perhaps in a representative subset of participating hospitals. Collection of baseline QoL data is an important methodological consideration in emergency surgery research: employing a baseline timepoint following the immediate acute event may potentially enable collection of QoL in a greater proportion of patients. Timing of 'baseline' data collection in the emergency setting needs further research.

\section{Conclusions}

The ELFUS study affirms the feasibility of collecting PROMs and morbidity data successfully at a number of time points following surgery. This is the first longitudinal study to describe PROMs and QoL up to a year following emergency general abdominal surgery. The ELFUS study demonstrates that it is possible to capture baseline PROMS data in the emergency setting by changing the timing of the initial assessment, whilst demonstrating low rates of attrition for longitudinal assessments. Post-operative morbidity data can be defined and graded appropriately and collected in the emergency setting when standardised scoring systems are employed. These methodological considerations can be employed in a larger study to collect PROMs and morbidity data and to assess the impact of emergency laparotomy on these important outcomes. Further work is needed to assess the optimum timing of baseline assessments of QoL. Any future research should consider how to reduce recruitment bias, ensuring all emergency laparotomy patients are included in assessments of the impact of surgery on their recovery and subsequent quality of life.

\section{Supplementary Information}

The online version contains supplementary material available at https://doi. org/10.1186/s13741-021-00193-5.
Additional file 1:. Complication scoring and assessment tools.
Additional file 2:. Quality of life assessment tools.
Additional file 3:. Number of respondents to WHODAS domains at candidate time points (landscape table only).
Additional file 4:. Number of respondents to EQ5D domains at candidate follow up timepoints (portrait table only).
Additional file 5: Additional file 5: Proportion of respondents reporting levels 1-5 in EQ5D at candidate follow up points (portrait table only).
Additional file 6:. Additional file 6: Respondents reporting EQ5D problems or no problems at candidate follow up points (portrait table only).

\section{Acknowledgements}

Not applicable

\begin{abstract}
Authors' contributions
DS, RS: design, approvals, patient contact, analysis of data, major contribution to manuscript. BG: Accordion Severity Grading, analysis of data, major contribution to manuscript. EP: analysis of data, major contribution to manuscript. DH: major contribution to manuscript. BS: design of results database, review of manuscript. HR, CS: patient contact and data collection, review of manuscript. All authors read and approved the final manuscript.
\end{abstract}

\section{Funding}

This project was supported by a grant awarded from AAGBI/Anaesthesia via the National Institute for Academic Anaesthesia.

\section{Availability of data and materials}

The datasets used and analysed during this study are stored securely in our institution and available from the corresponding author on reasonable request.

\section{Declarations}

Ethics approval and consent to participate

The study protocol was approved by the Newcastle and North Tyneside Regional Ethics Committee (16/NE/0334) and sponsored by Newcastle upon Tyne Hospitals NHS Foundation Trust. Written informed consent was taken from each participant, or alternatively from their proxy in the situation where sedation and ventilation prevented capacity to give consent. Participant consent was gained retrospectively for these individuals once capacity was regained.

\section{Consent for publication}

All authors give their permission and consent for publication of this manuscript and its additional files.

\section{Competing interests}

DIS, RCFS, EP, DH, BS, HR, CS declared that they have no competing interests.

\section{Author details}

'Department of Anaesthesia, Royal Victoria Infirmary, Newcastle upon Tyne NHS FT, NE1 4LP, UK. ${ }^{2}$ Department of Colorectal Surgery, Royal Victoria Infirmary, Newcastle upon Tyne NHS FT, NE1 4LP, UK. ${ }^{3}$ Newcastle University, Newcastle upon Tyne NE2 4HH, UK. ${ }^{4}$ Research Nurse, Department of Research and Development, Royal Victoria Infirmary, Newcastle upon Tyne NHS FT, NE1 4LP, UK. 
Received: 19 June 2020 Accepted: 26 April 2021

Published online: 26 July 2021

\section{References}

Chalmers I, Clarke M. Outcomes That Matter to Patients in Tombstone Trials. Lancet. 2001;358:1649. https://doi.org/10.1016/s0140-6736(01)06689-2.

EuroQol Research Foundation. EQ-5D, 2019. Available at https://euroqol.org (accessed 16/10/2019).

Glance LG, Osler TM, MD. N. Redesigning Surgical Decision Making for High-Risk Patients. New Eng J Med. 2014;370(15):1379-81. https://doi.org/10.1056/ NEJMp1315538.

Grocott MP, Browne JP, Van der Meulen J, Matejowsky C, Mutch M, Hamilton MA, et al. The Postoperative Morbidity Survey was validated and used to describe morbidity after major surgery. J Clin Epidemiol. 2007;60(9):919-28. https://doi. org/10.1016/j.jclinepi.2006.12.003.

Howes TE, Cook TM, Corrigan LJ, Dalton SJ, Richards SK, Peden CJ. Postoperative morbidity survey, mortality and length of stay following emergency laparotomy. Anaesthesia. 2015;70(9):1020-7. https://doi.org/10.1111/anae.12 991.

Khuri SF, Henderson WG, DePalma RG, Mosca C, Healey NA, Kumbhani DJ, et al. Determinants of long-term survival after major surgery and the adverse effect of postoperative complications. Ann Surg. 2005;242(3):326-41 discussion 41-3.S.

Kwong E, Black N. Feasibility of collecting retrospective patient reported outcome measures (PROMs) in emergency hospital admissions. J Patient Rep Outcomes. 2018;2(1):54. https://doi.org/10.1186/s41687-018-0077-y.

Kwong E, Neuburger J, Murray D, Black N. Feasibility of collecting and assessing patient-reported outcomes for emergency admissions: laparotomy for gastrointestinal conditions. BMJ Open Gastroenterology. 2018;5(1):e000238. https://doi.org/10.1136/bmjgast-2018-000238.

Mason JD, Blencowe NS, McNair AG, Stevens DJ, Avery KN, Pullyblank AM, et al. Investigating the collection and assessment of patient-reported outcome data amongst unplanned surgical hospital admissions: a feasibility study. Pilot Feasibility Stud. 2015;1(1):16. https://doi.org/10.1186/s40814-015-0011-5.

Myles PS, Boney O, Botti M, Cyna AM, Gan TJ, Jensen MP, et al. Systematic review and consensus definitions for the Standardised Endpoints in Perioperative Medicine (StEP) initiative: patient comfort. Br J Anaesth. 2018;120(4):705-11. https://doi.org/10.1016/j.bja.2017.12.037.

National Emergency Laparotomy Audit. https://www.nela.org.uk (accessed 15/10/ 2019). . 2019.

NELA Inclusion Criteria. 2013. Available at https://data.nela.org.uk/Support/NELA Inclusion-Exclusion-Criteria-Yr4.aspx (accessed 16/10/2019).

Parmar KL, Law J, Carter B, Hewitt J, Boyle JM, Casey P, et al. Frailty in Older Patients Undergoing Emergency Laparotomy: Results From the UK Observational Emergency Laparotomy and Frailty (ELF) Study. Ann Surg. 2021;273(4):709-18.

Patient Reported Outcome Measures. NHS Digital. Last edited 24/2/20. Available at https://digital.nhs.uk/data-and-information/data-tools-and-services/dataservices/patient-reported-outcome-measures-proms. (accessed 15/10/19) (n.d.)

Prytherch DR, Whiteley MS, Higgins B, Weaver PC, Prout WG, Powell SJ. POSSUM and Portsmouth POSSUM for predicting mortality. Br J Surg. 1998;85(9):121720. https://doi.org/10.1046/j.1365-2168.1998.00840.x.

Saunders DI, Murray D, Pichel AC, Varley S, Peden CJ. Variations in mortality after emergency laparotomy: the first report of the UK Emergency Laparotomy Network. Br J Anaesth. 2012;109(3):368-75. https://doi.org/10.1093/bja/aes165.

Shulman MA, Myles PS, Chan MTV, Mcllroy DR, Wallace S, Ponsford J. Measurement of disability-free survival after surgery. Anesthesiol. 2015;122(3): 524-36. https://doi.org/10.1097/ALN.0000000000000586.

Sim J, Lewis M. The size of a pilot study for a clinical trial should be calculated in relation to considerations of precision and efficiency. J Clin Epidemiol. 2012; 65(3):301-8. https://doi.org/10.1016/j.jclinepi.2011.07.011.

Stevens DJ, Blencowe NS, McElnay PJ, Macefield RC, Savovic J, Avery KN, et al. A systematic review of patient-reported outcomes in randomized controlled trials of unplanned general surgery. World J Surg. 2016;40(2):267-76. https:// doi.org/10.1007/s00268-015-3292-1.

Strasberg SM, Linehan DC, Hawkins WG. The accordion severity grading system of surgical complications. Ann Surg. 2009;250(2):177-86. https://doi.org/10.1 097/SLA.0b013e3181afde41.

Tengberg LT, Cihoric M, Foss NB, Bay-Nielsen M, Gögenur I, Henriksen R, et al. Complications after emergency laparotomy beyond the immediate postoperative period - a retrospective, observational cohort study of 1139 patients. Anaesthesia. 2017;72(3):309-16. https://doi.org/10.1111/anae.13721.

Tolstrup M-B, Watt SK, Gögenur I. Morbidity and mortality rates after emergency abdominal surgery: an analysis of 4346 patients scheduled for emergency laparotomy or laparoscopy. Langenbeck's archives of surgery. 2017;402(4): 615-23. https://doi.org/10.1007/s00423-016-1493-1.

World Health Organization. WHO Disability Assessment Schedule 2.0 (WHODAS 2. 0), 2018. https://www.who.int/classifications/icf/whodasii/en/ (accessed 16/ 10/2019).

\section{Publisher's Note}

Springer Nature remains neutral with regard to jurisdictional claims in published maps and institutional affiliations.
Ready to submit your research? Choose BMC and benefit from:

- fast, convenient online submission

- thorough peer review by experienced researchers in your field

- rapid publication on acceptance

- support for research data, including large and complex data types

- gold Open Access which fosters wider collaboration and increased citations

- maximum visibility for your research: over $100 \mathrm{M}$ website views per year

At BMC, research is always in progress.

Learn more biomedcentral.com/submissions 